\title{
The Visualization Research of User Observation and Quantitative Information
}

\author{
ZhangXin, FangHai, HuFei \\ School Of Art And Design Guangdong University of Technology, Guangzhou,China

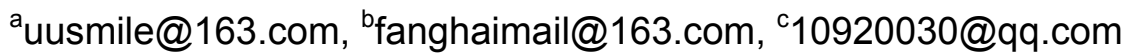

Keywords: user research, user observation, information, visualization

\begin{abstract}
User observation is a significant method for user research. Researchers collect information by field observation. Information collecting and analysis to information observed effects structure analyzing and innovative design of products directly. It visualizes the research results, eliminates interference information, unnecessary information and images and conveys useful information briefly and correctly, which makes the results more vivid. In order to benefit the future product development, this thesis, based on this purpose, mainly studies the better methods to visualize the research information of users.
\end{abstract}

\section{Introduction}

In product design, user-centered means users are the first element to consider in all procedures. They are the users of products, software and services. In the initial stage of product cycle, as the basic motivation and final purpose, product strategies should meet users' demands; then in the rest process of product development, product strategies should be on the basis of studies and understanding to users. Celtic, the professor on relevant field held that "focusing on users or user statistics is seen as the product source of a design motivation and assessment criteria of design results." Celtic's definition is related to the preciseness of users' statistics and effectiveness of data in the process of using. Data analysis of users is the hardest stage of user research to implement in the course of design because of the influence of various uncertainties on accuracy of data. So the stage of user research uses complementary qualitative and quantitative analysis.

\section{Methods for User Studies}

Different methods are used in different situations. In the term of industrial design, the methods include observation, inquiry, experiment and so on.

\section{Observation}

Observation of users' behavior shows how much users like the product. Materials to improve the products are collected according to observe the operating procedures and habits of users when they use the products. This method makes the information more objective, which avoids some subjective assumes and helps to get intuitional and real materials.

\section{Inquiry}

This method is widely used in various researches. It, also called questionnaire, is a method of collecting information by interviewing interviewees, including four types: face-to-face interview, telephone interview, emailing questionnaires and online interview. They are all indirect inquiry in which researchers don't contact with interviewees directly.

\section{Experiment}

It means the samples to be produced are linked to the formal marketing activities with an experiment to make the products contact directly with market and clients informally and to study the effects of all kinds of elements to market by controlling their changes. So the researchers can study the subjects repeatedly to get accurate results in order to reduce the market risk of products efficiently. 


\section{Daily Record of Users' Images}

It refers to a method to choose some relevant activities, within a week, in the daily life of family members and about products to be researched. They consist of every aspect of the products, warts and all, and find the relationship between specific products and a certain behavior in life. Then the author finds the apparent similarities and individualities by comparing the scenes of life among those samples chosen.

Except the methods above, others can be adopted in researches, such as in-depth interview, image stories, contrast, filtration and recall.

\section{Quantification and Visualization of Research Data of Users}

\section{Research Data of Users}

"Data" always reminds people of "number", "table", "model", or "equation". Virtually, the real meaning of "data" is those "people" behind. In the stage of quantitative questionnaire, the author conducts market survey to users with organized materials. Having got feedback, the author cleanses, analyzes and interprets the information. This project needs visualize the details in the survey and describe the project overall to maintain the continuity of the research. Those archived and neglect-prone details are recorded into research report to show the research results and to communicate with clients.

\section{Methods and Procedures of Data Analysis}

Data analysis is the important thing in user research, which deals with the original data collected in the process of survey appropriately to reflect the relationship among data and data processed. The methods used are mainly those techniques about data analysis.

Firstly, the author shows data initially organized in tables and then understands and organizes data. In the stage of collecting data, the importance of target should be explicit. The only way to interpret and understand data is to analyze target clearly because of the quantity of information containing in data.

Secondly, proper statistic analysis technique should be chosen due to the importance to decide that which statistic analysis is suitable for handling problems. Based on classification, statistical index should be found to deal with problems, the rest of which are solved by calculation.

\section{Effects of Visual Information}

The nature of tables is to present boring data with direct and vivid visual effects to reveal and prove some assumptions. According to user survey, the author gets some users' information and data which need to be analyzed and organized to extract useful information. These data should be transferred into tables or visual images and then to demonstrate research results with videos, pictures or some other forms.

\section{Tables Demonstrating Quantitative Relations}

Histogram, most frequently used type of table, mainly shows the data changes over a period of time and the comparison among all kinds of data. The same to histogram, bar chart also shows the situation among data, but it prefers to the comparison of quantities over the time.
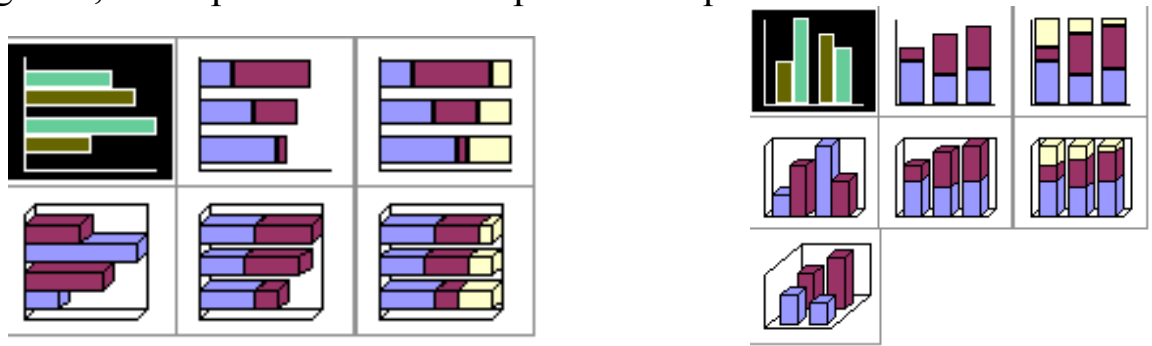

Figure 1 Histogram

Tables Demonstrating Tendencies

Line chart presents the change tendency of relevant quantities over a period of time with broken lines. Stressing practicability and rate of change, it is suitable for showing and analyzing data 
tendency in equal time. Area graph manifests data tendency changed with time with differences of area. It can also present total value tendency of all data.

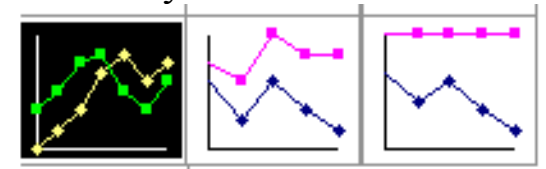

Figure 2 Line Chart

Charts Demonstrating Proportional Relations

Pie chart is generally used to show the proportion relationship among all kinds of data with sum total $100 \%$. Each sector in pie chart means an item of the data. Pie chart can only analyze one column of data, while doughnut can be used to elaborate the proportional relations among data.

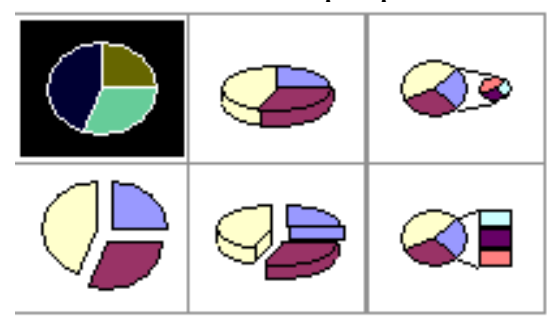

Figure 3 Pie Chart

Applications of Other Charts

Scatter diagram synthesizes the data down the abscissa and that down the ordinate into single data points. It shows some coupled data with uneven gaps or cluster. Bubble diagram is the variant of scatter diagram. In bubble diagram, data points are presented by bubbles and the size of bubbles means another data cubes. So what bubble diagram compares is the three numbers in a group. Radar chart is also named spider web or star chart, which can be used when several indexes in one subject are described or analyzed
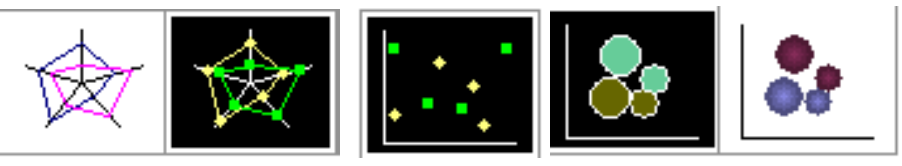

Figure 4 Scatter, Bubble and Radar Charts

These pie chart, histogram and scatter chart are the most original charts. They are the most basic and frequently used charts in data visualization. As a tool in statistics, statistical graphics is a shortcut to know dataset quickly. Being a convincing communication way, it can convey the basic information in data. As a result, statistical graphics is always used to analyze users' questionnaire.

Yet the most basic statistical graphics are only capable of presenting the basic information, finding the structures among data and visualizing the quantitative data results. The situations need to be solved of data visualization are much more complicated facing complex or large-scale abnormal-shape dataset, for instance users' behavior data and so on. Therefore, data processing needs to go through a set of complex steps of data processing which includes data collection, data analysis, data governing, data organizing and data mining. After that, the designers design a pattern of manifestation which can be planar, tridimensional, two-dimensional, dynamic, real-time or even interactive.

\section{Visualizing the Information Got from User Studies}

The fundamental purpose of information visualization is to convey information clearly and efficiently by images. It doesn't mean the design of boring functional charts because of functions, neither the design of magnificent pictures because of aesthetics. In order to deliver information, aesthetics should keep pace with functions to analyze and express abundant complex information with direct visual approaches. 


\section{Improvement of SNR (Signal to Noise Ratio) of Visual Information}

\section{Definition of SNR}

All the communication will involve the creativity, transmission and reception of information, among which the signals of relevant information are decreased yet the noise is increased in each phase. Due to the changes of information, "decreasing" of information refers to the decreasing of clarity of useful information. The elimination degree of information means the proportion of useful information and useless information. For instance, SNR in a chart without relevant elements is pretty high; SNR in a chart with lots of relevant elements is quite low. The purpose of a good design is to produce a maximum SNR to make the noise to the minimum.

\section{How to Enhance Visual Information}

"Increasing the signal to the maximum" means to deliver information as clearly as possible with minimum noise. "Decreasing signal" will emerge if information is presented inefficiently, such as vague articles, improper pictures or implicit images and expressions. "Clear signal" will be strengthened if information is presented briefly. Simple design brings tiny "efficiency load", making people notice the meaning of information intently. Study and cautious decision decline the "signal decreasing" to the minimum. For example, meanings of information will be mistaken essentially if there are no correct images to express specific information. As a result, it is very important to make correct decision about design at the beginning. It should be tested if necessary to confirm accurate design. "Signal decreasing" can also be descended by stressing the important aspects of information. For instance in design, the ways like "emphasizing" or "being an alternate" can be adopted.

"Decreasing the noise to the minimum" means to eliminate those useless elements and demonstrate those useful elements as simply as possible. One of the most important is that each unnecessary information, picture, line or token can detract people from relevant elements. This kind of roundness should be avoided or eliminated. On the premise of maintaining functions, necessary roundness should be dropped to the minimum. All the elements in the design should be presented as great as possible, but it cannot exceed the limitation, or it will turn to noise.

SNR should be as maximum as possible in design. The design should be simple to enhance signal and the strategies should be chosen cautiously. The ways like "emphasizing" or "being an alternate" can be taken into consideration to promote the significant aspects of information. If it is available, popular criteria and guidelines can be used to promote the changes of customs and moreover, it can be popularized greatly to make consumers use it permanently. Noise can be decreased by wiping off unnecessary elements and presenting necessary elements simply.

\section{Avoiding Meaningless Visual Information}

The aim of data visualization and information visualization is to exchange information more efficiently and clearly with images. Vivid, explicit and attractive charts can be created to help users understand the implications or changes of data quickly with beautiful colors or animations. However, it doesn't mean that data charts become boring and complex because of its practicability and gorgeousness. Great appearance and internal functions are inevitable in order to convey ideas efficiently. 


\section{Case Studies of User Observation and Information Visualization Information Visualization with Charts}

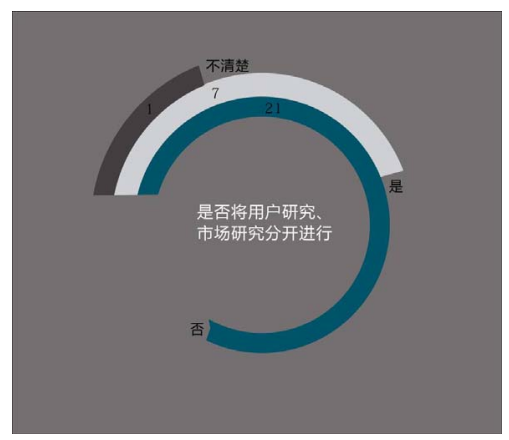

Figure 5. Relation between User research and Market Research

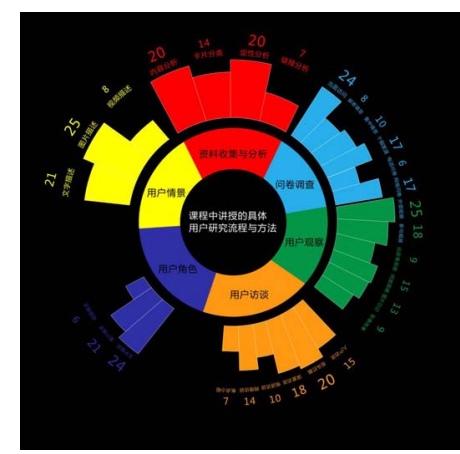

Figure 6. Detailed Procedures and Methods of User Studies Taught in Curriculum

Figure 5 is the circular transformation expression of one-dimensional data in the coordinate. The variant is whether user research and market research can be studies separately. The information agent is three possibilities.

Figure 6 shows the detailed procedures and methods of user studies taught in curriculum with double-deck annulus and the relative operating frequency of each method

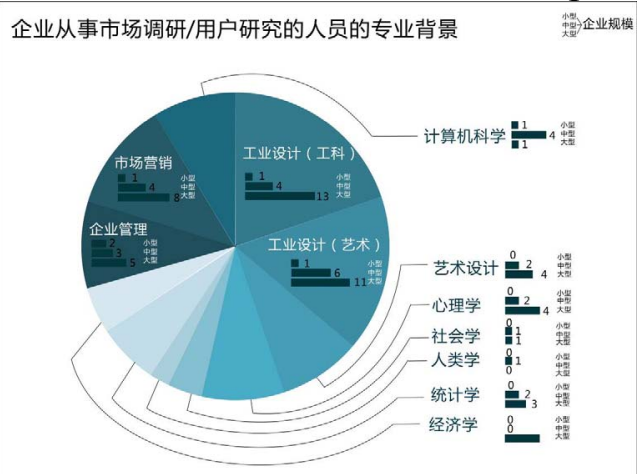

Figure 7. Professional Background of

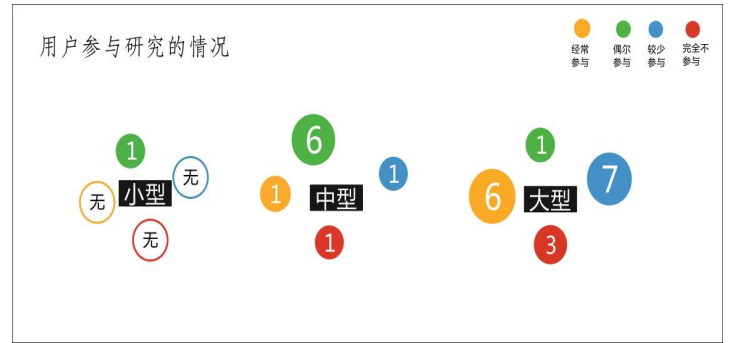

Figure 8. Situations of User Studies

Researchers Studying Users /Market

Figure 7 expresses the professional backgrounds of researchers who study users and market in different sizes of companies with pie chart and histogram.

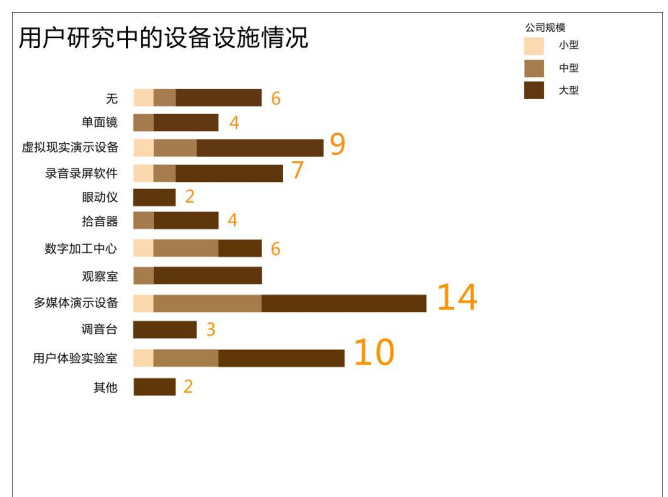

Figure 9 Facilities in User Researches

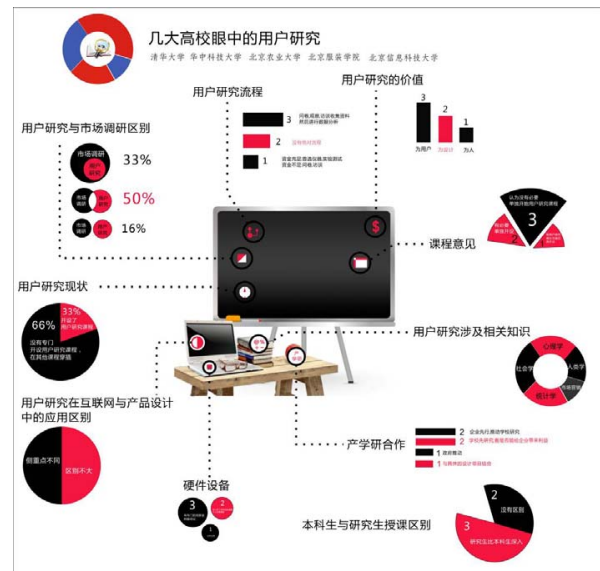

Graph 10. User Research in the Eyes of Several Universities

According to the comparison of case studies, efficient visualization to deal with data can simplify data and clarify data structures. More and deeper information can be acquired by efficient contrast.

Applied procedures of visualization with charts:

(1) Set goals: Confirm the information need to know according to the given topic 
(2) Set information agent and associate attribute: Confirm the information agent and associate attribute needed on the basis of goals.

(3) Set the basic structures of visualization: Confirm the patterns of manifestation and basic structures of visualization according to the number of information agent and associate attribute.

(4) Make visual images: Present efficient visual images by different ways, free-hand sketches or computer software.

(5) Analysis of visualization: Analyze visual images according to the relation demonstrated by diagrams and the original targets of questions.

Visualization studies of information acquired from user interview.

Collect and analyze the questionnaire in earlier user research, choose the survey doubts and the questions which cannot be resolved only by questionnaire to deeply research the typical users. The purpose of user interview is to develop the cognition of target users to the subjects to reap their opinions by the deep interview of one or several target users.

The materials got from user interviews are sort of disperse and the conversation style in the interviews is kind of oral because of the need of interviews, so in the process of material organization, the interview data should be quantified and compared to a degree according to the aim of interview to make the opinions of users reflected by information more implicit and easier to be understood.

What is showed below is the visual organization and analysis of information in a group of user interview. It also describes the visual and analysis procedures of interview materials.

Table 1

\begin{tabular}{|c|c|}
\hline & $\begin{array}{l}\text { 10. Nowadays, internal user research is still in a theoretical } \\
\text { stage. There is a question that how that balance the theoretical } \\
\text { input and practical output. How do you think to conduct the } \\
\text { cooperation of production, study and research in the field of user } \\
\text { research? }\end{array}$ \\
\hline \begin{tabular}{l}
\multicolumn{2}{c}{ Professor Gao Bingxue } \\
Director of Department of \\
Industrial Design \\
(Beijing \\
Science Information \\
University)
\end{tabular} & $\begin{array}{l}\text { The best way is to build a platform with the money from } \\
\text { government. It contains the projects the enterprises demand. Then } \\
\text { it is implemented by schools with some research grants. Put the } \\
\text { achievements on the platform to provide references for the } \\
\text { enterprises. }\end{array}$ \\
\hline $\begin{array}{l}\text { Associate professor Liu Sha } \\
\text { (Beijing }\end{array}$ & $\begin{array}{l}\text { The most important to carry out cooperation of products, study } \\
\text { and research is to see the profits the user research brings, while the } \\
\text { internal user research is still in the initial period with low } \\
\text { profitability. }\end{array}$ \\
\hline $\begin{array}{l}\text { Dr. Chen Xiaohua } \\
\text { Director of Department of } \\
\text { Industrial Design } \\
\text { (Beijing Institute of } \\
\text { Clothing Technology) }\end{array}$ & $\begin{array}{l}\text { The first thing to do is to arouse the enthusiasm of enterprises. } \\
\text { They should work with schools and cultivate some fundamental } \\
\text { talents to prepare for latter study. }\end{array}$ \\
\hline $\begin{array}{l}\text { Professor Liu Jikun } \\
\text { (Tsinghua University) }\end{array}$ & $\begin{array}{l}\text { The most significant about cooperation of products, study and } \\
\text { research should begin from the enterprises. Then schools go to } \\
\text { study because of the demands and projects of enterprises. }\end{array}$ \\
\hline $\begin{array}{l}\text { Associate professor Cao Huai } \\
\text { (Huazhong University of } \\
\text { Science and Technology) }\end{array}$ & $\begin{array}{l}\text { What is principal is to see whether the researches of schools meet } \\
\text { the demands of enterprises, but at present, most of the schools are } \\
\text { not professional enough in user research. It is easy to enforce the } \\
\text { researches if cooperation of products, study and researches } \\
\text { connects with product design. }\end{array}$ \\
\hline $\begin{array}{l}\text { Dr. Lei Tian } \\
\text { (Huazhong University of }\end{array}$ & It is easy to study if detailed projects are linked together. \\
\hline
\end{tabular}




\begin{tabular}{|l|l|}
\hline Science and Technology) & $\begin{array}{l}\text { Generally, it is said that cooperation of products, study and } \\
\text { researches should be conducted because of the relevant demands } \\
\text { of enterprises and schools' abilities to meet these demands. } \\
\text { However, user research hasn't been perfect yet. Single study } \\
\text { cannot bring profit for enterprises, so this cooperation should be } \\
\text { associated with detailed designing project. }\end{array}$ \\
\hline
\end{tabular}

Notes: Part of the original materials comes from "Ministry of education of humanities and social science research project---User research path and method of industrial design industry in China", item number: 10YJC60028, project leader: Hu Fei.

The original charts show ten interview questions, value of user research, procedures of user research, differences between user research and market survey, current situation of user research, distinction of user research in internet and product design, suggestions of curriculum, relevant knowledge involved in user research, cooperation of products, study and researches, curriculum differences between undergraduates and postgraduates, hardware equipment, opinions of six target groups to these ten questions. Initially, the author presents the different individual ideas with charts, compares questions with text description and summarizes her own viewpoints. Nevertheless, current description summarizes the advice and attitudes of users being interviewed partially and the results are not convincing enough. Graph 10 shows the improvement.

Design procedures: Firstly, original materials are processed preliminarily. Each question or each group of questions focuses on one topic due to the characteristics of interview questions: limited number and profundity. After definite topic has been confirmed based on the prior questions, interview details based on this topic are classified and organized, and then different viewpoints and percentages are marked in details and quantified. Entire visual style is determined according to the entire topic of interview after the confirmation of information. For instance, the core topic should be classroom if the interview is about school teaching. Then distinct visual expressions are to be confirmed on the basis of different details of subtopics and the number of integrated information. In the end, the several subtopics are permuted and combined according to the core topic to accomplish a complete visual project.

Detailed analysis: there are six subjects participating in the deep interview. The entire environment is classroom because the topic is about the viewpoints of user research from different designing colleges and universities. Different subtopics determine the visual expressions being quantified or described differently according to the ideas and percentages of information.

The interviews include value of user research, procedures of user research, differences between user research and market survey, current situation of user research, suggestions of curriculum, relevant knowledge involved in user research, distinction of user research in internet and product design in user research. The author gets lots of written information and verbal suggestions. Finally, the results are shown by data organization and information visualization to reflect the details of information efficiently and to improve SNR.

This case manifests the shortage of persuasion and prominence to the key points with single texts and organization of descriptive materials. Macroscopically, entire visual processing can help to observe categories of viewpoints on different topics and the percentages of each category, which makes the transmission efficiency whopping improved.

Visual procedures:

(1) Get original materials and classify different questions into different topics according to the questions in the original materials and interview purpose.

(2) Mark the different opinions in each topic.

(3) Confirm the visual forms of topics according to he categories of opinions and the percentages of each category.

(4) Confirm the entire style, permute subtopics according to the details of entire topics to form an entire visual form.

(5) Analyze the charts according to the relations shown in the images. 
Conclusion:

The author gets some users' information and data by user research. The results should be presented with videos, pictures instead of those simple charts which need to be turned into tables or visual images. Imaging makes information communication more efficiently and clearly. Vivid and attractive charts can be built with beautiful colors and animations to help users understand the implications and change of data quickly. However, it doesn't mean that data charts are boring and complex because of their practicability and gorgeousness. It's more brief and clear to express important information with the elimination of unnecessary elements.

\section{Conclusion}

The author gets some users' information and data by user research. The results should be presented with videos, pictures instead of those simple charts which need to be turned into tables or visual images. Imaging makes information communication more efficiently and clearly. Vivid and attractive charts can be built with beautiful colors and animations to help users understand the implications and change of data quickly. However, it doesn't mean that data charts are boring and complex because of their practicability and gorgeousness. It's more brief and clear to express important information with the elimination of unnecessary elements.

\section{Acknowledgments}

Project and Fund Support:

Provincial Science and Technology Planning Project in 2013;

Projects of Introduction of Innovative Research in Guangdong Province in 2011.

\section{References}

[1] 胡飞. 聚焦用户UCD观念与实务[M]. 1. 中国建筑工业出版社, 2009年10月.

[2] 杨向东. 工业设计程序与方法[M]. 1. 高等教育出版社, 2008年1月.

[3] [英]DavidMccandless（大卫·麦克坎德莱斯）著. 信息之美[M]. 1. 电子工业出版社, 2012年4 月。

[4]（美）托比, 等著祝洪凯, 等译. 数据之美[M]. 1. 机械工业出版社, 2010年10月.

[5] 胡飞. 洞悉用户: 用户研究方法与应用[M]. 1. 中国建筑工业出版社, 2010年8月.

[6] 董建明 / 傅利民 / [美]沙尔文迪. 人机交互: 以用户为中心的设计和评估[M]. 1. 清华大学出 版社, 2013-9. 